\title{
Study of opening emergency safety as a PE optional course in regular Colleges
}

\author{
Xia lun \\ Department of physical education ,Hua Zhong Agricultural University, \\ Wu han,Hu bei,china, 430070 \\ xialun521@sina.com
}

\begin{abstract}
Through a large number of literature study, questionnaire survey of university students and expert interview, the investigation and detailed analysis on the current situation of carrying out emergency survival education in Colleges and universities. On this basis, put forward to carrying out the emergency safety education curriculum in Colleges and universities, and in the curriculum to teach a man to fish than giving the teaching method of fishing to establish the university emergency safety teaching mode. To arouse college students life safety consciousness, from the treasure and cherish own life to cherish and care for the lives of others, in order to strengthen and improve college students' protection ability and strain capacity.
\end{abstract}

Keywords-emergency safety education; sports elective courses; curriculum reform

\section{INTRODUCTION}

In today's society, a variety of natural disasters and disaster occurred frequently, emergency safety courses ( the teaching content of earthquake escape, fire prevention, drowning rescue, wound treatment and dressing 、 cardiopulmonary resuscitation ) in foreign countries have been very popular. From a variety of journals and literature can be seen, foreign study on emergency safety courses and school to promote knowledge of student safety awareness and self rescue have formed deep system of theory and practice . In Japan, life curriculum pays great attention to escape, it proposed the establishment of " security, peace of mind " teaching philosophy, emergency safety course is an important education and training courses from primary school to university. The famous American educator Huang quanyu through long-term observation and in-depth study on the United States of America family and school education of survival, published " survival education in a book " about the United States of America. He put the children on survival education summarized into six rules of survival. In addition, he also described the role of the United States of America " SCOUT " organization in child survival education and encourage domestic parents and school education for children to take a similar pattern.

With the deepening reform of Chinese physical education and the full implementation of the national fitness program, people have a new understanding of the school sports, the " New elements " to expand the teaching content of physical education curriculum has become an inevitable trend of College Physical Education reform. According to our country present stage the occurrence of various disasters such as the 08 years of the 5.12 Wen chuan earthquake, Yu shu earthquake and the occurrence of various types of fire drowning event continuously. The sports curriculum emergency safety into school education is the urgent need of the present stage of our country education reform. But in the current school physical education system has not been understanded fully, the author through to the Chinese Journal Full-text Database ( CNKI ), retrieved Wan fang Chinese Dissertations Full-text Database and superstar digital library website, have found that the number of escape and rescue method is not much, the life and study escape method is relatively simple, such as Wang Ning's " the current situation and Countermeasures of school fire safety work discussion ", Luo Zhiyong " College Students' apartment fire hazard and its preventive measures ", Shi Yupeng " thinking of China's high school crisis management system -- from the " 5.12 "Wenchuan earthquake ". Most of the articles with the method related to escape and rescue have been not researched, and further to a variety of research related to escape and rescue method and the university sports teaching organically is scarcely any, only find Hou Qian

《physical education should strengthen the students to develop the ability of emergency escape 》, Zheng Songping, Zhou Xudong 《survival education and College Physical Education 》 and Yu Hua 《how to escape,survival skills into regular school Games 》 and other research. From the above situation, teaching content of sports safety education program emergency has not mature theory system and its theoretical system is still not perfect.

\section{THE OBJECT AND METHOD OF RESEARCH}

\section{A. Research objects:}

300 undergraduates form universities like Hua Zhong Agricultural University, Wuhan University, Hua Zhong University of Science and Technology and Wuhan University of Polytechnology

\section{B. Research methods}

(1) The literature: Consulted and collected a large number of domestic and foreign relevant emergency safety course books, websites, magazines and newspapers 
articles such as a large number of data, and provides a theoretical basis for the development of convenient writing process.

(2) The expert interview: Ask 5 relevant experts, checks and inspection the questionnaire validity and reliability ; second analysis the feasibility of physical education curriculum of emergency safety, the effectiveness of teaching contents, reasonable and scientific teaching evaluation.

(3) Questionnaires: Distributed to College Students of 300 questionnaires, 293 questionnaires were recovered, excluding 5 invalid questionnaires, effective recovery 288 copies of effective questionnaires, the rate of recovery was $96 \%$. Acceptance survey of College Students' understanding of the emergency safety education and carry out the emergency safety sports teaching in Colleges and universities.

(4) Method of comparative analysis: Comparison and analysis the domestic and foreign related emergency safety curriculum development, provide ideas and direction of China's colleges and universities to carry out the course.

\section{RESULTS AND ANALYSIS}

A. The basis set the curriculum of emergency safety physical education in Colleges and universities

In 1972, the chairman of committee of the international education development Edgar Faure published entitled " How to survive -- the world of education today and tomorrow " report. The report proposed "learning to be to lifesaving " slogan. The essence of survival education is to enable students to learn how to survive, let the students formed a set of suitable for their own survival program.

General Secretary $\mathrm{Hu}$ Jintao puts forward "The disaster prevention and other scientific knowledge into the spirit of the important instructions of national education". Our sports workers to combination of sports and health course characteristics of the safety education into the daily teaching system, let the students master the basic skills to deal with disasters, develop an escape path for students. In 2008 the State Council of the first national day of disaster prevention and reduction ( May 12th) the theme is " raise disaster prevention awareness, enhance skills to escape ". Now all over the country to exercise " escape and lifesaving" activities. The contents of this course has strong pertinence and practice, through the implementation of emergency security course to arouse the college students life safety consciousness education of the contemporary college students, to let them master the most in need of modern society and the life fitness knowledge and skills to escape, let the students more benefit from the course teaching.

Deputies to the National People's Congress,
Huazhong Normal University doctoral tutor Zhou Hongyu pointed out: " survival education includes not only the safety education in the usual sense, is also included in the disaster, people can judge according to the accident scene, using the basic knowledge and skills of self-rescue and escape, avoid risks, , save themselves from the scene. "

$B$. The role and function of developing emergency safety physical education curriculum

(1) the educational function of developing emergency security physical education curriculum -- through the sports curriculum emergency safety teaching, so that students can master first aid skills and methods, The best way to escape your own at his finge rtip, in case of emergency to act quickly, to quickly self-help, mutual rescue, as far as possible to win the escape time, to maximize the maintenance of their own safety.

(2) The needs of the curriculum reform -- Sports teaching is the best carrier for on-site emergency rescue and escape education. At present, teach first aid and escape skills has become an international consensus in the school sports, the school should take emergency escape safety education as a necessary work to do. PE unique learning style and content, determine the sports discipline is very suitable for emergency escape self-help knowledge teaching.

(3) enrich the teaching content of Physical Education -- Based on the students about the earthquake, fire prevention, to avoid drowning rescue, treatment of wound and wound and cardiopulmonary resuscitation and so on several unit teaching in the teaching process, combining with theory and practice, by setting up special teaching scenarios, put a few unit organically related binding, let the students learn in practice, to practice in learning.

\section{The goals of the emergency safety P.E curriculum in} Colleges and universities

(1) The knowledge goal: through the " escape and rescue " course of study, enable students to have a scientific and reasonable understanding on emergency situation, using a variety of related knowledge of the reasonable and scientific to deal with emergency escape and rescue technology.

(2) The ability goal: through "escape and lifesaving" course of study, students can make an effective analysis of unexpected events, cultivate the ability to use a variety of ways and means can solve unexpected events in special environment.

(3) The attitude goal: through the "escape and lifesaving" course, stimulate students' interest in learning, the development of the students to pay attention to the surrounding environment, cultivating students' love and protect environment moral ability. At the same time in the course of the learning process, students and others, solidarity and cooperation, jointly solve the emergency of the emotion objectives. 


\section{THE TEACHING ARRANGEMENT AND CONTENTS OF THE EMERGENCY SAFETY CURRICULUM}

Since entering the classroom curriculum emergency safety as a new sports item, how to establish teaching syllabus, teaching content, teaching target and the teaching organization is an urgent problem facing us. This article is a research on the colleges and universities sports curriculum emergency safety teaching aim, teaching content and organization. In the teaching of the attempt to combine theory and practice, through a variety of teaching situations and teaching settings, to enable students to master the most in need of modern society and the life fitness health knowledge and skills to escape and rescue. Teaching arrangement with specific settings as shown .

College physical education curriculum settings can put the sports emergency safety curriculum as elective course, the curriculum can be divided into theory and practice courses.

In the theory curriculum, make full use of multimedia teaching means and the focus on students in sports that are likely to occur abrasion, contusion, laceration, muscle strain, fracture and dislocation, injury and on preventive measures; explain and describes how to help the injured students skills and Method; fixed wounded classmates joints and carrying the wounded when the attention matters in basic knowledge. gradual strengthen on-site emergency and escape consciousness.

In the practice curriculum, make full use of the game, competition; set up the scene of hemostasis 、 bandaging, fixing simulation 、 carrying the wounded a artificial respiration、cardiopulmonary resuscitation, also can put a single scene together, such rescue and CPR as drowning combined to simulate the hemostasis, bandage; fixed and reasonable transportation of the wounded, to enable students to master the correct method of rescue. Let students understand knowledge at the same time the master first aid skills. The creation of earthquake, fire and other natural disasters scene walk through, let students experience the strain ability, strain and strategy in case of emergency escape skills. These activities not only let the students master the knowledge, improve knowledge, but also cultivate students' team cooperation ability.

\section{MAKING SYSTEMATIC TEACHING PROGRAM 、TEACHING SCHEDULE AND TEACHING PLAN ABUT THE EMERGENCY SAFETY PHYSICAL EDUCATION TEACHING}

Establish "health first" guiding ideology to implement the school sports work, the full implementation of quality education, to promote the healthy development of students, and train qualified personnel, all-round development, according to the national Ministry of Education promulgated the " National Ordinary College Sports Curriculum Teaching
Instruction Summary "of the spirit and the implementation of the " Huazhong Agricultural University sports curriculum syllabus ", in summing up the experience of other sports school based curriculum construction and teaching reform in Colleges and universities, establishing the system of emergency security PE teaching plan, teaching schedule and teaching plan.

\section{THE ASSESSMENT OF THE EMERGENCY SAFETY P.E CURRICULUM IN COLLEGES AND UNIVERSITIES}

escape and rescue course assessment can be divided into theory and practice examination. Theory evaluation should focus on the seismic escape, fire prevention, drowning rescue, cardiopulmonary resuscitation and the related knowledge of wound treatment master degree of understanding and judgment. In practice course examination of the simulated teaching scene should pay attention to test students' ability and teamwork ability and jointly solve the emergency ability. In short, the teaching evaluation should be based on the development of students' cognitive development level and the ability of emotion as the focus of the curriculum of physical education in Colleges emergency safety, from the point of view of knowledge and skill, process and method of constructing the appraisal model.

\section{CONCLUSION}

(1) Set up the curriculum of physical education teaching in emergency safety in Colleges and universities, closely contact and cooperate other departments such as the tuan wei, hospital, the school security department and so on in the teaching, scientific construction of school emergency safety education integration system.

(2) The needs of Curriculum design optimization is to proceed from the reality of education system in our country, the maximum value for the course, To achieve the best effect of curriculum design. From the reality that according to our country in recent year snowstorm, earthquake and fire accidents, according to the actual situation of the students' physical and mental development carry on curriculum design.

(3) In the sports curriculum of emergency safety, through set up various events in the teaching scene, so that students in a variety of complex and changeable situation adjust to changing circumstances 、 rapid response 、 timely action, improve students' ability of sensitive reaction, and make the teaching content rich and colorful, so that students can " edutainment ".

\section{ACKNOWLEDGMENT}

※ Central university basic scientific research business expenses for special fund project "Study of 
opening emergency safety as a PE optional course in regular colleges" (2011RW027)

Author's brief introduction : Xia Lun (1981-),male ,lecturer;

Research direction: physical education and training.E-mail: xialun521@sina.com

\section{REFERENCE}

[1] Ji Baocheng. Look at the universities crisis management [J]. China higher education research from "SARS " prevention and control, 2003
[2] Qin Qiwen et al. The prevention and response of Emergency[M] . Beijing: Xinhua press, 2008

[3] Shi Yupeng. Thinking of perfecting the university crisis management system in China -- from the " 5.12" Wenchuan earthquake [J]. The era of economic and trade, 2008.12.

[4] Luo Zhiyong [J] Journal of student apartment fire hazards and Prevention Countermeasures of colleges and universities [J] Xiang tan Teachers College ( NATURAL SCIENCE EDITION ), 2009.3.

[5] Shi Yupeng. Thinking of perfecting the university crisis management system in China -- from the " 5.12" Wenchuan earthquake [J]. The era of economic and trade, 2008.12.

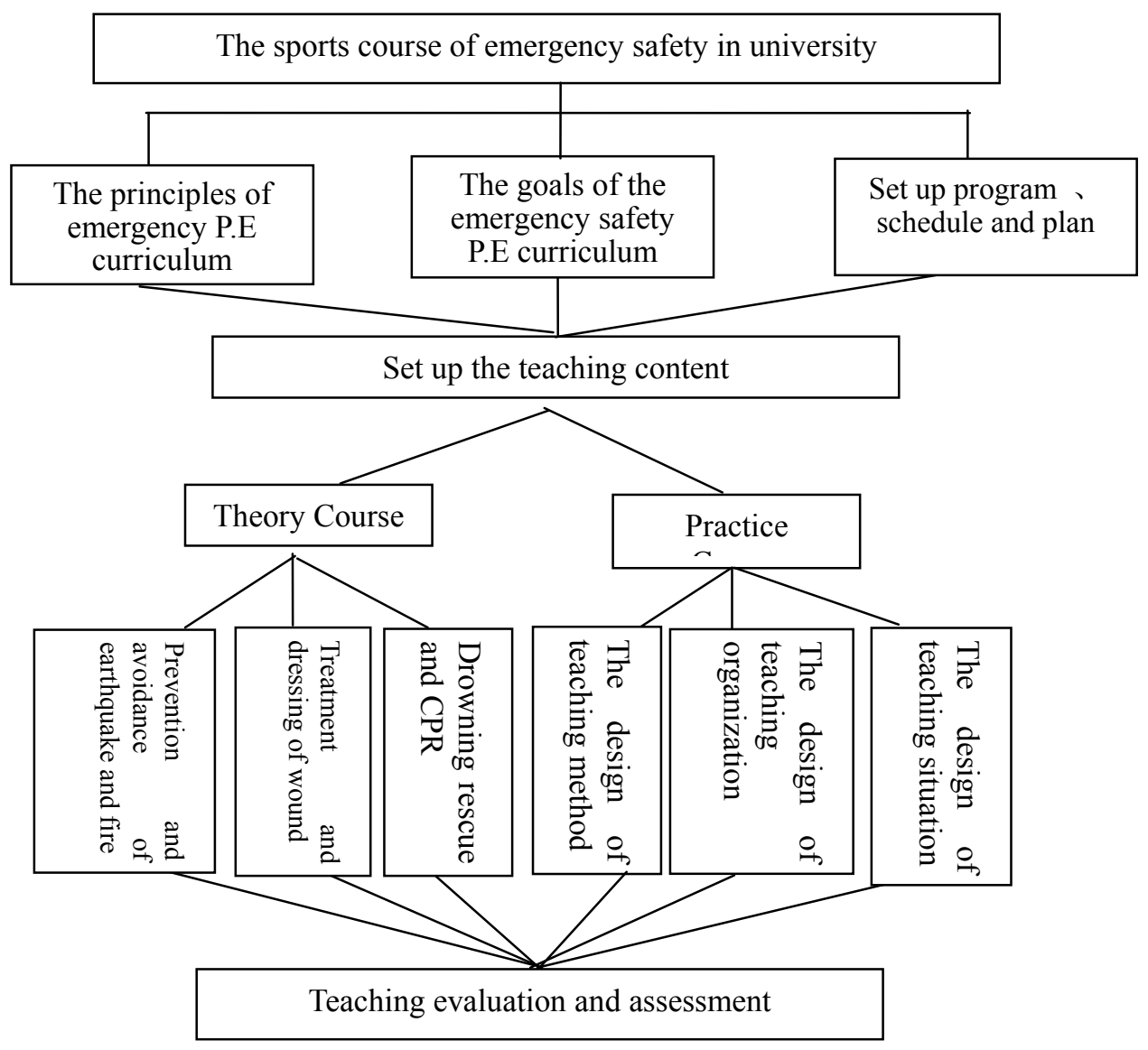

Fig.1 Diagram of Teaching evaluation and assessment 